\title{
Adjuvant Chemotherapy in Microsatellite Instability-High Gastric Cancer
}

\author{
Jin Won Kim, MD, PhD' \\ Sung-Yup Cho, MD, PhD2,3 \\ Jeesoo Chae, $\mathrm{PhD}^{2}$ \\ Ji-Won Kim, MD, MS \\ Tae-Yong Kim, MD, PhD ${ }^{3,4}$ \\ Keun-Wook Lee, MD, PhD' \\ Do-Youn Oh, MD, PhD 34 \\ Yung-Jue Bang, MD, $P h D^{3,4}$ \\ Seock-Ah Im, MD, PhD',4
}

${ }^{1}$ Division of Hematology and Medical Oncology, Department of Internal

Medicine, Seoul National University Bundang

Hospital, Seoul National University College of

Medicine, Seongnam, ${ }^{2}$ Department of

Biomedical Sciences, Seoul National

University College of Medicine, Seoul,

${ }^{3}$ Cancer Research Institute, Seoul National

University College of Medicine, Seoul,

${ }^{4}$ Division of Hematology and Medical

Oncology, Department of Internal Medicine,

Seoul National University Hospital, Seoul

National University College of Medicine,

Seoul, Korea

Correspondence: Seock-Ah Im, MD, PhD

Department of Internal Medicine,

Seoul National University College of Medicine,

101 Daehak-ro, Jongno-gu, Seoul 03080, Korea

Tel: 82-2-2072-0850

Fax: 82-2-765-7081

E-mail: moisa@snu.ac.kr

Received April 14, 2020

Accepted June 10, 2020

Published Online June 11, 2020

\begin{abstract}
Purpose
Microsatellite instability (MSI) status may affect the efficacy of adjuvant chemotherapy in gastric cancer. In this study, the clinical characteristics of MSI-high (MSI-H) gastric cancer and the predictive value of MSI-H for adjuvant chemotherapy in large cohorts of gastric cancer patients were evaluated.
\end{abstract}

\section{Materials and Methods}

This study consisted of two cohorts. Cohort 1 included gastric cancer patients who received curative resection with pathologic stage IB-IIIC. Cohort 2 included patients with MSI-H gastric cancer who received curative resection with pathologic stage II/III. MSI was examined using two mononucleotide markers and three dinucleotide markers.

\section{Results}

Of 359 patients (cohort 1), 41 patients (11.4\%) had MSI-H. MSI-H tumors were more frequently identified in older patients $(p<0.001)$, other histology than poorly cohesive, signet ring cell type $(p=0.005)$, intestinal type $(p=0.028)$, lower third tumor location $(p=0.005)$, and absent perineural invasion ( $p=0.027$ ). MSI-H status has a tendency of better diseasefree survival (DFS) and overall survival (OS) in multivariable analyses (hazard ratio [HR], $0.4 ; p=0.059$ and HR, $0.4 ; p=0.063$, respectively). In the analysis of $162 \mathrm{MSI}-\mathrm{H}$ patients (cohort 2), adjuvant chemotherapy showed a significant benefit with respect to longer DFS and $\mathrm{OS}$ ( $p=0.047$ and $p=0.043$, respectively). In multivariable analysis, adjuvant chemotherapy improved DFS (HR, 0.4; $p=0.040)$.

\section{Conclusion}

MSI-H gastric cancer had distinct clinicopathologic findings. Even in MSI-H gastric cancer of retrospective cohort, adjuvant chemotherapy could show a survival benefit, which was in contrast to previous prospective studies and should be investigated in a further prospective trial.

\section{Key words}

Microsatellite instability, Adjuvant chemotherapy, Stomach neoplasms

\section{Introduction}

Microsatellite instability (MSI) is characterized as the increased rate of uncorrected replication errors at the simple repeat sequence caused by a DNA mismatch repair gene (MMR) defect [1,2]. MSI-high (MSI-H) results in accelerated mutations in oncogenes and tumor suppressor genes and a phenotype of hypermutational status [3,4]. Tumor-specific neopeptides may be generated during MSI-H carcinogenesis.
A protective role of lymphocytes against MSI-H colorectal cancer that prevents tumor metastasis was reported [5]. Because of the immunologic aspect of MSI status, it was recently highlighted as a predictive marker in immunotherapy. MSI-H tumors have been shown to benefit from immunotherapy, and anti-programmed death-1 antibody (pembrolizumab) has finally been approved by the U.S. Food and Drug Administration for the treatment of MSI-H tumors regardless of the tumor type [6,7]. 
In an adjuvant setting, MSI-H could be a prognostic and predictive marker. In colorectal cancer, MSI-H tumor showed better prognosis than microsatellite stable (MSS)/MSI-low (MSI-L) tumors [8,9]. Patients with MSI-H colorectal cancer did not benefit from adjuvant chemotherapy. Particularly, adjuvant chemotherapy with 5-fluorouracil alone in patients with stage II colorectal cancer may be even worse than no adjuvant chemotherapy [8]. Therefore, adjuvant chemotherapy with 5-fluorouracil alone in stage II colorectal cancer patients is not recommended by several guidelines [10,11].

In gastric cancer, adjuvant chemotherapy with capecitabine plus oxaliplatin or S1 has been proven to prolong survival after D2 resection of stage II/III gastric cancer in CLASSIC and ACTS-GC study [12,13]. MSI-H status is relatively common in gastric cancer and occurs in approximately $9 \%$ of surgically resected gastric cancer [4,14-16]. In the CLASSIC trial, compared with the overall positive results, patients with MSI$\mathrm{H}$ gastric cancer did not experience any survival benefit from adjuvant chemotherapy $[13,15]$. Similarly, in the MAGIC trial, which evaluated the role of perioperative chemotherapy for resectable gastric cancer, MSI-H status had an improved prognosis in the surgery-alone treatment arm, but a worse survival outcome in the chemotherapy-plus-surgery arm compared with an MSS/MSI-L [17,18]. A recently published paper of pooled individual patient data from four large randomized clinical trials conducted in patients with resectable gastric cancer (MAGIC [18], CLASSIC [13], ARTIST [19] which evaluated the concurrent irradiation with adjuvant chemotherapy [capecitabine plus cisplatin], and ITACA-S [20] which evaluated an intensified combination chemotherapy schedule [fluorouracil plus leucovorin plus irinotecan followed by cisplatin plus docetaxel] compared with single-agent chemotherapy [fluorouracil plus leucovorin]) showed that patients with MSI-L/MSS gastric cancer benefited from chemotherapy plus surgery, but those with MSI-H gastric cancer did not [16]. However, in the CLASSIC and MAGIC trial, only 40 and 20 patients had MSI-H tumors. In a pooled analysis of four clinical trials, 121 patients had MSI-H tumors, and just 33 patients with MSI-H tumor who received surgery alone were included in the control group. Therefore, despite these results from randomized clinical trials and pooled analysis, there is limited statistical power for the use of MSI/MMR deficiency testing as a predictive marker for adjuvant chemotherapy in patients with curatively resected gastric cancer.

Therefore, we evaluated the predictive value of MSI-H tumor for the benefit of adjuvant chemotherapy in large cohorts of gastric cancer patients. The clinical characteristics of MSI-H gastric cancer were also evaluated.

\section{Materials and Methods}

\section{Patients}

This study consisted of two cohorts. In cohort 1, the clinical features of MSI-H compared with MSS/MSI-L were analyzed. Cohort 1 included gastric cancer patients who received curative resection with pathologic stage IB-IIIC from February 2005 to January 2006 at Seoul National University Hospital (SNUH). Cohort 2 was used for the analysis of the efficacy of adjuvant chemotherapy in MSI-H gastric cancer. Cohort 2 included patients with MSI-H gastric cancer who received curative resection with pathologic stage II/ III from January 2007 to February 2012 at Seoul National University Bundang Hospital (SNUBH) and from December 2004 to June 2012 at SNUH. MSI-H patients in cohort 1 were included in cohort 2. Clinical data were retrieved from the medical records of patients. The American Joint Committee on Cancer (AJCC) 7th edition was used.

\section{Test for MSI}

Genomic DNA of the formalin-fixed gastric cancer tissues was extracted using standard proteinase-K digestion and a phenol/ chloroform procedure. MSI was examined using two mononucleotide markers: BAT 25 (located 4q12-13 KIT gene, intron 16, T25 repeat) and BAT 26 (located 2p22-21, hMSH2 gene, exon5, A26 repeat) and three dinucleotide markers: DS123 (located 2p 16.3, CA repeat), D5S346 (located 5q22.2, CA repeat), and D17S250 (located 17q12, CA repeat). Polymerase chain reaction (PCR) reactions were conducted in $10 \mu \mathrm{L}$ reaction volumes with fluorescent dye 50-end labeled primers. PCR products were denatured in formamide for 2 minutes at $95^{\circ} \mathrm{C}$ and electrophoresed on denaturing $8 \%$ polyacrylamide sequencing gels. MSI status was analyzed using GeneScan software in an ABI 3100 sequencer (Foster City, CA). Tissue samples that exhibited abnormal band patterns were considered to indicate MSI. According to the number of markers displaying instability of each tumor, the tumors were divided into MSI-H, MSI-L, and MSS. MSI-H indicated instability in two or more of five markers. MSI-L indicated instability in one of five markers. MSS indicated there was no instability in the five markers [1].

\section{Statistical analysis}

The differences in clinicopathologic findings according to MSI status were evaluated using chi-square analysis. Diseasefree survival (DFS) was defined as the duration between the surgical operation and disease relapse, any cause of death before disease relapse, or the last follow-up. The event for DFS was defined as relapse and any cause of death. Overall survival (OS) was measured from the surgical operation to the last follow-up or any cause of death. The event for OS was defined as any cause of death. The Kaplan-Meier method was used for survival analysis with the log-rank test. The Cox 
Table 1. Characteristics of gastric cancer patients with MSS / MSI-L and MSI-H (cohort 1)

\begin{tabular}{|c|c|c|c|}
\hline Characteristic & $\begin{array}{c}\text { MSS/MSI-L } \\
(\mathrm{n}=318,88.6 \%)\end{array}$ & $\begin{array}{c}\text { MSI-H } \\
(\mathrm{n}=41,11.4 \%)\end{array}$ & p-value \\
\hline \multicolumn{4}{|l|}{ Age (yr) } \\
\hline Median (range) & $60(28-87)$ & & \\
\hline$<70$ & $269(92.4)$ & $22(7.6)$ & $<0.001$ \\
\hline$\geq 70$ & $49(72.1)$ & $19(27.9)$ & \\
\hline \multicolumn{4}{|l|}{ Sex } \\
\hline Male & $214(90.7)$ & $22(9.3)$ & 0.083 \\
\hline Female & $104(84.6)$ & $19(15.4)$ & \\
\hline \multicolumn{4}{|l|}{ Operation } \\
\hline Total gastrectomy & $109(93.2)$ & $8(6.8)$ & 0.066 \\
\hline Subtotal gastrectomy & $191(85.3)$ & $33(14.7)$ & \\
\hline Partial gastrectomy & $17(100)$ & 0 & \\
\hline Whipple & $1(100)$ & 0 & \\
\hline \multicolumn{4}{|l|}{ Histology } \\
\hline Tubular, well to poorly differentiated & $253(86.9)$ & $38(13.1)$ & 0.045 \\
\hline Poorly cohesive, signet ring cell type & $42(100)$ & 0 & \\
\hline Other histological variants & $23(88.5)$ & $3(11.5)$ & \\
\hline \multicolumn{4}{|l|}{ Lauren $^{\text {a) }}$} \\
\hline Diffuse & $126(92.0)$ & $11(8.0)$ & 0.028 \\
\hline Intestinal & $147(84.0)$ & $28(16.0)$ & \\
\hline Mixed & $42(95.5)$ & $2(4.5)$ & \\
\hline \multicolumn{4}{|l|}{ Location } \\
\hline Upper third & $21(100)$ & 0 & 0.005 \\
\hline Mid third & $169(92.3)$ & $14(7.7)$ & \\
\hline Lower third & $128(82.6)$ & $27(17.4)$ & \\
\hline \multicolumn{4}{|l|}{ Stage } \\
\hline $\mathrm{Ib}$ & $65(85.5)$ & $11(14.5)$ & 0.285 \\
\hline IIA & $71(85.5)$ & $12(14.5)$ & \\
\hline IIB & $56(90.3)$ & $6(9.7)$ & \\
\hline IIIA & $36(83.7)$ & $7(16.3)$ & \\
\hline IIIB & $58(95.1)$ & $3(4.9)$ & \\
\hline IIIC & $32(94.1)$ & $2(5.9)$ & \\
\hline \multicolumn{4}{|l|}{ Lymphatic } \\
\hline Absent & $127(92.7)$ & $10(7.3)$ & 0.054 \\
\hline Present & $191(86.0)$ & $31(14.0)$ & \\
\hline \multicolumn{4}{|l|}{ Venous } \\
\hline Absent & $271(88.0)$ & $37(12.0)$ & 0.386 \\
\hline Present & $47(92.2)$ & $4(7.8)$ & \\
\hline \multicolumn{4}{|l|}{ Perineural } \\
\hline Absent & $136(84.5)$ & $25(15.5)$ & 0.027 \\
\hline Present & $182(91.9)$ & $16(8.1)$ & \\
\hline \multicolumn{4}{|l|}{ Adjuvant chemotherapy } \\
\hline Not applied & $143(78.1)$ & $40(21.9)$ & 0.113 \\
\hline Applied & $149(84.7)$ & $27(15.3)$ & \\
\hline
\end{tabular}

Values are presented as number $(\%)$ unless otherwise indicated. ${ }^{a}$ Unknown patients $(n=3)$.

proportional hazards regression model was used to calculate hazard ratio (HR) in univariable and multivariable analysis. All statistical analyses were performed using SPSS Statistics ver. 25 (IBM Corp., Armonk, NY).

\section{Ethical statement}

This study was conducted in accordance with the ethical standards of the Declaration of Helsinki and the national and international guidelines. This study was approved by the institutional review board at SNUBH (B-1207-164-107) and 


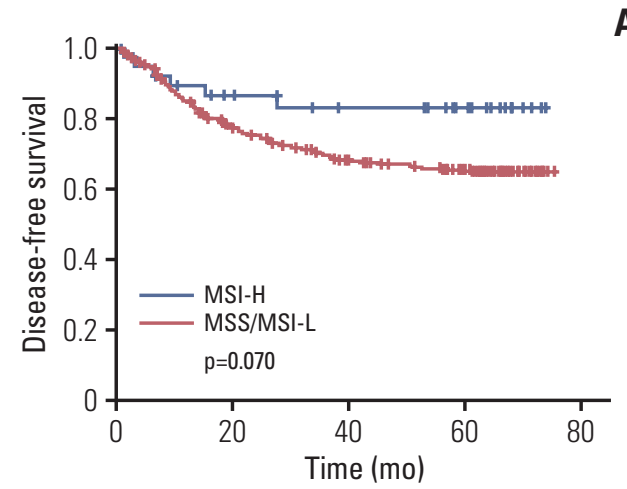

A

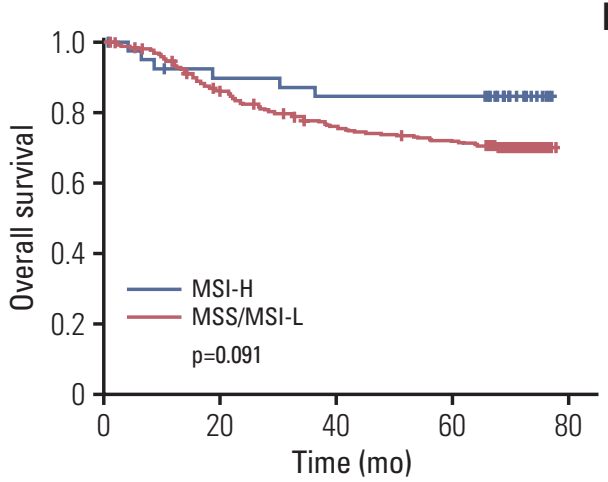

Fig. 1. Disease-free survival (A) and overall survival (B) according to microsatellite instability (MSI) status. p-value calculated by a KaplanMeier method. MSI-H, MSI-high; MSI-L, MSI-low; MSS, microsatellite stable.

SNUH (H-1208-100-422) and acquired a waiver of informed consent.

\section{Results}

1. Characteristics of patients with MSI-H gastric cancer compared with MSS/MSI-L gastric cancer (cohort 1)

Cohort 1 was analyzed to evaluate the characteristics of MSI-H gastric cancer patients who received curative gastrectomy. A total of 731 patients with gastric cancer received the curative operation with D2 dissection. Among these patients, 366 patients with stage IA were excluded. MSI data were available in 359 of 365 patients with stages IB-IIIC. Cohort 1 consisted of these 359 patients (Table 1). MSI-H status was seen in 41 patients (11.4\%) and was associated with older age ( $27.9 \%$ vs. $7.6 \%, \mathrm{p}<0.001$ ), other histology than poorly cohesive, signet ring cell type ( $\mathrm{p}=0.045)$, Lauren's intestinal type ( $16 \%$ vs. $8.0 \%$ of disuse type, $\mathrm{p}=0.028$ ), and lower third tumor location (17.4\% vs. $7.7 \%$ of mid-third location, $\mathrm{p}=0.005)$. In contrast, there were no patients who had MSI-H tumors with poorly cohesive, signet ring cell type $(0 / 42,0.0 \%)$. There was no significant correlation according to stage $(\mathrm{p}=0.285)$, lymphatic invasion $(\mathrm{p}=0.054)$, or venous invasion $(\mathrm{p}=0.386)$, but MSI-H was identified more frequently in absent perineural invasion $(\mathrm{p}=0.027)$.

\section{Survival of patients with MSI-H gastric cancer compared with MSS/MSI-L gastric cancer (cohort 1)}

In cohort 1 , the median follow-up duration was 71.1 months after surgery. Univariable analysis between clinicopathologic factors and survival was done (S1 Table). Patients with MSI$\mathrm{H}$ gastric cancer had better 5-year DFS rate $(83.2 \%$ vs. $65.5 \%$, respectively; $\mathrm{p}=0.070)$ (Fig. $1 \mathrm{~A})$, and 5 -year OS rate ( $84.4 \%$ vs. $71.7 \%$, respectively; $\mathrm{p}=0.091$ ) (Fig. 1B) than those with MSS / MSI-L, although there was not significant. In the multivariable analysis with MSI status, sex, age, World Health Organi- zation histology, Lauren classification, tumor location, lymphatic invasion, venous invasion, perineural invasion, and the use of adjuvant chemotherapy, MSI-H status showed an better survival although there was not statistical significance (for DFS: HR, 0.4; 95\% confidence interval [CI], 0.2 to 1.0; $\mathrm{p}=0.059$; for OS: HR, $0.4 ; 95 \%$ CI, 0.2 to $1.0 ; \mathrm{p}=0.063$ ) (Table 2).

In terms of the role of adjuvant chemotherapy in MSS/ MSI-L tumors, patients with adjuvant chemotherapy had the prolonged survival (for DFS: $p=0.176$ and $p<0.001$; for OS: $p=0.225$ and $p<0.001$ in stage II and stage III, respectively). However, in MSI-H tumors, patients with adjuvant chemotherapy did not show the prolonged survival because of small sample size (for DFS: $\mathrm{p}=0.439$ and $\mathrm{p}=0.836$; for OS: $\mathrm{p}=0.439$ and $\mathrm{p}=0.933$ in 18 patients with stage II and 12 stage III, respectively).

\section{Characteristics of MSI-H gastric cancer patients (cohort 2)}

We next evaluated the efficacy of adjuvant chemotherapy in more MSI-H gastric cancer patients who received a curative gastrectomy (cohort 2). In total, 5,983 patients were screened who received a gastrectomy and an MSI test. Of these 5,983 patients, 578 patients $(9.7 \%)$ were confirmed as MSI-H. Finally, 162 patients who underwent R0 resection, were diagnosed with pathologic stage II/III, and were a candidate for adjuvant chemotherapy were included in cohort 2 (S2 Fig.). The baseline characteristics of these patients are shown in Table 3. In this cohort, $38.9 \%$ of patients were over 70 years old, and $58 \%$ were male. Tumor location of the lower third was observed in $62.3 \%$. Intestinal type was found in $52.5 \%$. All patients had MSI-H gastric cancer, and $69.8 \%$ of patients showed instability in all five MSI markers. Pathologic stage II and stage III were identified in $77(47.5 \%)$ and $85(52.5 \%)$, respectively. Lymph invasion, vascular invasion, and perivascular invasion were identified in $77.8 \%, 15.4 \%$, and $37.7 \%$, respectively. In addition, 75 patients $(46.3 \%)$ were not treated with adjuvant chemotherapy. Fluoropyrimidine treatment alone, such as $\mathrm{S} 1$ or uracil and tegafur/leucovorin, 
Table 2. Multivariable analysis for disease-free survival and overall survival (cohort 1)

\begin{tabular}{|c|c|c|c|c|c|c|c|}
\hline \multirow[b]{2}{*}{ Characteristic } & \multirow[b]{2}{*}{ No. } & \multicolumn{3}{|c|}{ Disease-free survival } & \multicolumn{3}{|c|}{ Overall survival } \\
\hline & & $\begin{array}{c}\text { Hazard } \\
\text { ratio }\end{array}$ & $\begin{array}{c}95 \% \\
\text { Confidence } \\
\text { interval }\end{array}$ & p-value ${ }^{\text {a) }}$ & $\begin{array}{c}\text { Hazard } \\
\text { ratio }\end{array}$ & $\begin{array}{c}95 \% \\
\text { Confidence } \\
\text { interval }\end{array}$ & p-value ${ }^{a}$ \\
\hline \multicolumn{8}{|l|}{ MSI } \\
\hline MSS or MSI-L & 318 & 1 & & & 1 & & \\
\hline MSI-H & 41 & 0.4 & $0.2-1.0$ & 0.059 & 0.4 & $0.2-1.0$ & 0.063 \\
\hline \multicolumn{8}{|l|}{ Sex } \\
\hline Male & 291 & 1 & & & 1 & & \\
\hline Female & 68 & 0.5 & $0.3-0.9$ & 0.010 & 0.6 & $0.4-1.0$ & 0.051 \\
\hline \multicolumn{8}{|l|}{ Age (yr) } \\
\hline$<70$ & 236 & 1 & & & 1 & & \\
\hline$\geq 70$ & 123 & 1.6 & $0.9-2.6$ & 0.091 & 1.9 & $1.1-3.3$ & 0.017 \\
\hline \multicolumn{8}{|l|}{ Histology } \\
\hline Poorly cohesive, signet ring cell type & 42 & 1 & & & 1 & & \\
\hline Other & 317 & 1.1 & $0.7-1.7$ & 0.779 & 0.9 & $0.5-1.4$ & 0.535 \\
\hline \multicolumn{8}{|l|}{ Lauren } \\
\hline Diffuse & 137 & 1 & & & 1 & & \\
\hline Intestinal & 175 & 0.7 & $0.4-1.1$ & 0.114 & 0.7 & $0.4-1.1$ & 0.129 \\
\hline Mixed & 44 & 1.0 & $0.5-1.8$ & 0.943 & 1.0 & $0.5-1.8$ & 0.939 \\
\hline \multicolumn{8}{|l|}{ Location } \\
\hline Upper third & 21 & 1 & & & 1 & & \\
\hline Mid third & 183 & 1.0 & $0.4-2.5$ & 0.943 & 3.0 & $0.7-12.4$ & 0.135 \\
\hline Lower third & 155 & 1.1 & $0.4-2.8$ & 0.844 & 3.7 & $0.9-15.6$ & 0.073 \\
\hline \multicolumn{8}{|l|}{ Stage } \\
\hline $\mathrm{Ib}$ & 76 & 1 & & & 1 & & \\
\hline II & 145 & 2.8 & $1.0-7.5$ & 0.044 & 4.1 & $1.2-14.2$ & 0.025 \\
\hline III & 138 & 14.0 & $5.2-38.2$ & $<0.001$ & 20.0 & $5.8-69.6$ & $<0.001$ \\
\hline \multicolumn{8}{|l|}{ Lymphatic } \\
\hline Absent & 137 & 1 & & & 1 & & \\
\hline Present & 222 & 2.1 & $1.2-3.6$ & 0.010 & 1.8 & $1.0-3.2$ & 0.048 \\
\hline \multicolumn{8}{|l|}{ Venous } \\
\hline Absent & 308 & 1 & & & 1 & & \\
\hline Present & 51 & 2.5 & $1.6-3.9$ & $<0.001$ & 2.5 & $1.6-4.0$ & $<0.001$ \\
\hline \multicolumn{8}{|l|}{ Perineural } \\
\hline Absent & 161 & 1 & & & 1 & & \\
\hline Present & 198 & 1.1 & $0.7-1.7$ & 0.722 & 1.1 & $0.7-1.8$ & 0.734 \\
\hline \multicolumn{8}{|l|}{ Adjuvant chemotherapy } \\
\hline Not applied & 183 & 1 & & & 1 & & \\
\hline Applied & 176 & 0.4 & $0.3-0.7$ & $<0.001$ & 0.5 & $0.3-0.8$ & 0.005 \\
\hline
\end{tabular}

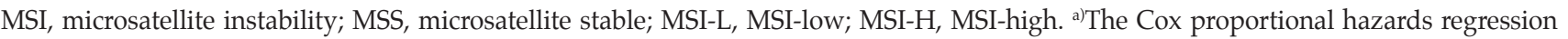
model was used.

was used in 42 patients (25.9\%), whereas 40 patients (24.7\%) were treated with fluoropyrimidine plus platinum, including 5-fluorouracil plus cisplatin or capecitabine plus oxaliplatin. There was no difference in the use of adjuvant chemotherapy by stage, but the application of adjuvant chemotherapy decreased significantly with age $(\mathrm{p}=0.521$ and $\mathrm{p}<0.001)$. Of the patients who were $\geq 80$ years old, $81.8 \%$ did not receive chemotherapy. In contrast, $82.4 \%$ of the patients under 60 years old were treated with adjuvant chemotherapy, and $51.0 \%$ received combination therapy with fluoropyrimidine and platinum $(\mathrm{p}<0.001)(\mathrm{S} 3 \mathrm{Table})$.

\section{Survival according to adjuvant chemotherapy in MSI-H gastric cancer patients (cohort 2)}

In cohort 2, the median follow-up duration was 87.9 months after surgery. Median DFS and OS of all patients 
Table 3. Characteristics of gastric cancer patients with MSI-H (cohort 2)

\begin{tabular}{|c|c|}
\hline Characteristic & o. $(\%)(n=162)$ \\
\hline \multicolumn{2}{|l|}{ Age (yr) } \\
\hline Median (range) & $66.5(37-95)$ \\
\hline$\leq 59$ & $55(34.0)$ \\
\hline $60-69$ & $44(27.2)$ \\
\hline $70-79$ & $52(32.1)$ \\
\hline$\geq 80$ & $11(6.8)$ \\
\hline \multicolumn{2}{|l|}{ Sex } \\
\hline Male & $94(58.0)$ \\
\hline Female & $68(42.0)$ \\
\hline \multicolumn{2}{|l|}{ Tumor location } \\
\hline Upper third & $16(9.9)$ \\
\hline Mid third & $41(25.3)$ \\
\hline Lower third & $101(62.3)$ \\
\hline Whole & $4(2.5)$ \\
\hline \multicolumn{2}{|l|}{ WHO classification } \\
\hline Tubular, well differentiated & $1(0.6)$ \\
\hline Tubular, moderately differentiated & $77(47.5)$ \\
\hline Tubular, poorly differentiated & $71(43.8)$ \\
\hline Other histological variants & $13(8.0)$ \\
\hline \multicolumn{2}{|l|}{ Lauren classification } \\
\hline Diffuse & $50(30.9)$ \\
\hline Intestinal & $85(52.5)$ \\
\hline Mixed & $27(16.7)$ \\
\hline \multicolumn{2}{|l|}{ Instable microsatellite marker } \\
\hline 2 & $18(11.1)$ \\
\hline 3 & $2(1.2)$ \\
\hline 4 & $29(17.9)$ \\
\hline 5 & $113(69.8)$ \\
\hline \multicolumn{2}{|l|}{ Pathologic stage } \\
\hline IIA & $19(11.7)$ \\
\hline IIB & $58(35.8)$ \\
\hline IIIA & $43(26.5)$ \\
\hline IIIB & $27(16.7)$ \\
\hline IIIC & $15(9.3)$ \\
\hline \multicolumn{2}{|l|}{ Lymphatic invasion } \\
\hline Absent & $36(22.2)$ \\
\hline Present & $126(77.8)$ \\
\hline \multicolumn{2}{|l|}{ Venous invasion } \\
\hline Absent & $137(84.6)$ \\
\hline Present & $25(15.4)$ \\
\hline \multicolumn{2}{|l|}{ Perineural invasion } \\
\hline Absent & $101(62.3)$ \\
\hline Present & $61(37.7)$ \\
\hline \multicolumn{2}{|l|}{ Adjuvant chemotherapy } \\
\hline No adjuvant therapy & $75(46.3)$ \\
\hline Fluoropyrimidine alone (S1, UFTE/LV) & $42(25.9)$ \\
\hline Fluoropyrimidine plus platinum (FP, XELOX) & $40(24.7)$ \\
\hline Unknown & $5(3.1)$ \\
\hline
\end{tabular}

MSI-H, microsatellite instability-high; WHO, World Health Organization; UFTE, uracil and tegafur; LV, leucovorin. were not reached. The result of univariable analysis between clinicopathologic factors and survival was shown in S4 Table. MSI-H patients treated with adjuvant chemotherapy showed longer DFS and OS than patients without chemotherapy $(\mathrm{p}=0.047$ and $\mathrm{p}=0.043$, respectively) (Fig. 2A and B). In MSI-H patients with stage II, this benefit of adjuvant chemotherapy was observed ( $\mathrm{p}=0.001$ in DFS, $\mathrm{p}=0.001$ in OS) but not in MSI$\mathrm{H}$ patients with stage III ( $\mathrm{p}=0.867$ in DFS, $\mathrm{p}=0.840$ in OS). In patients who received fluoropyrimidine alone, the 5-year DFS and OS rates were $87.0 \%$ and $94.8 \%$, respectively, which were higher than in the no adjuvant chemotherapy group (5-year DFS rate, 72.9\%; $\mathrm{p}=0.044$ [Bonferroni-corrected]; 5-year OS rate, 78.3\%; $\mathrm{p}=0.022$ [Bonferroni-corrected]) (Fig. $2 \mathrm{C}$ and $\mathrm{D}$ ). In the fluoropyrimidine plus platinum group, the 5 -year DFS and OS rates were $72.4 \%$ and $89.5 \%$, respectively, which were not significantly different from the no adjuvant chemotherapy ( $\mathrm{p}=0.880$ [Bonferroni-corrected] and $\mathrm{p}=0.956$ [Bonferroni-corrected], respectively). In addition, multivariable analysis with clinically significant factors, such as sex, age, stage, lymphatic invasion, venous invasion, perineural invasion, Lauren classification, and adjuvant chemotherapy, indicated that adjuvant chemotherapy in MSI-H gastric cancer patients was a significant independent prognostic factor for DFS (HR, $0.4 ; 95 \%$ CI, 0.2 to $1.0 ; \mathrm{p}=0.040$ ) (Table 4).

\section{Discussion}

In this study, the clinical features and predictive role of MSI-H for adjuvant chemotherapy were evaluated in curatively resected gastric cancer. MSI-H gastric cancer had a tendency of better prognosis than MSS/MSI-L after curative resection. In terms of the efficacy of adjuvant chemotherapy in MSI-H tumors, patients who received adjuvant chemotherapy could experience longer survival than those without adjuvant chemotherapy. Particularly, even adjuvant chemotherapy with fluoropyrimidine alone showed better survival than without adjuvant chemotherapy.

The clinical characteristics of MSI-H in curatively resected gastric cancer were distinctive from MSS/MSI-L. MSI-H tumor was diagnosed more frequently in older patients. In addition, MSI-H tumor was more common in patients with the intestinal type, other histology than poorly cohesive, signet ring cell type, and lower third tumor location. These findings were in accordance with previous studies $[14,16]$. In this study, MSI-H tumor was associated with present lymphatic invasion and absent perineural invasion. MSI was not correlated with early-stage cancers. This could be attributed to the exclusion of IA stage patients. In a previous study that included stage IA patients, MSI was observed more frequently in stage I (64.1\%; T1, 44.1\%; N0, 63.5\%). Among stage II/ III that were candidates for adjuvant chemotherapy, MSI-H was not observed frequently in earlier stage tumors [16]. 


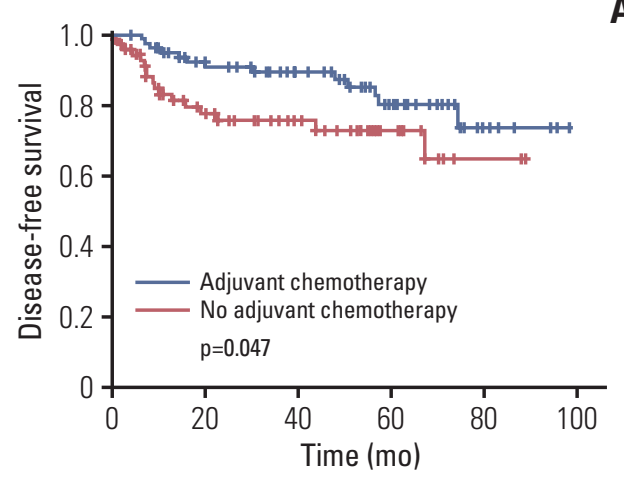

A
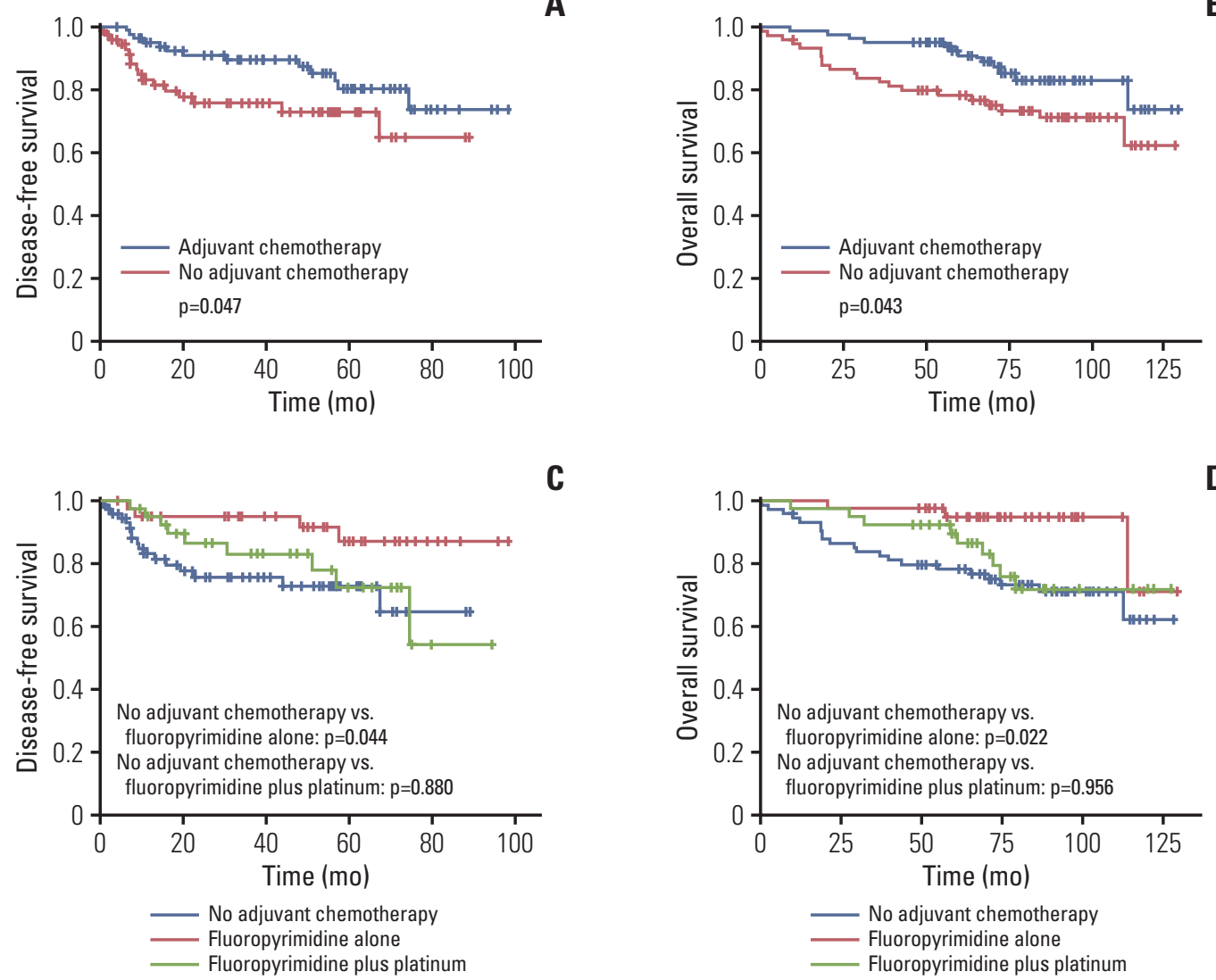

C

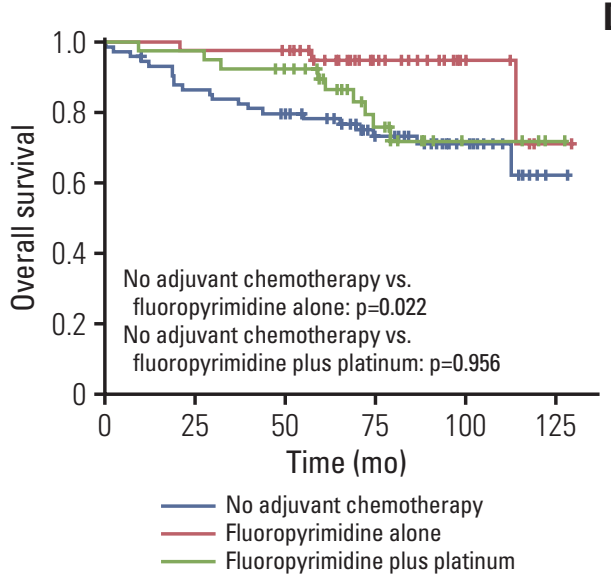

Fig. 2. Survival according to adjuvant chemotherapy in microsatellite instability-high gastric cancer. Bonferroni-corrected p-values, calculated by a Kaplan-Meier method. (A) Disease-free survival according to adjuvant chemotherapy. (B) Overall survival according to adjuvant chemotherapy. (C) Disease-free survival according to chemotherapy regimen. (D) Overall survival according to chemotherapy regimen.

MSI-H may be identified in just 7\%-9\% of resectable gastric cancers [14,16]. In the early stage that is not a candidate for adjuvant chemotherapy, MSI-H might be more frequently identified. Therefore, evaluation of the efficacy of adjuvant chemotherapy in MSI-H should be limited due to the small sample size. In previous studies related to the effects of adjuvant chemotherapy in MSI-H gastric cancer, only 40 and $20 \mathrm{MSI}-\mathrm{H}$ patients from the CLASSIC and the MAGIC study were included $[15,17]$. Just 33 MSI-H patients who received surgery alone and 88 patients with MSI-H tumor who received preoperative or adjuvant chemotherapy were included in the pooled analysis of four randomized trials [16]. In a retrospective study of a large cohort of 1,990 patients, just 54 patients with stage II/III were included for analysis of 5-fluorouracil adjuvant chemotherapy [14]. These studies demonstrated that MSI-H tumors did not benefit from adjuvant chemotherapy compared with MSS/MSI-L. However, due to small sample sizes, the use of these results to guide the application of adjuvant chemotherapy according to MSI status is limited. Although our study had a limitation due to its retrospective design, the population that was analyzed included 162 pathologic stage II/II patients with MSI-H tumor who were a candidate for adjuvant chemotherapy. This sample size was much larger than in previous studies. In contrast to previous studies, adjuvant chemotherapy could prolong the survival of patients, even in MSI-H gastric cancer. The efficacy of adjuvant chemotherapy in MSI-H patients could be an important clinical issue considering that MSI-H is more prevalent in older patients and those with an early stage of the disease. Therefore, this controversial result should be investigated in a further prospective study. Additionally, adjuvant chemotherapy with fluoropyrimidine alone showed a benefit in terms of survival, but fluoropyrimidine and platinum combination did not show better survival as an adjuvant therapy significantly. There was not significant effect of adjuvant chemotherapy in stage III in which more fluoropyrimidine and platinum combination was applied. Based on these findings of our study, platinum could be assumed to have a detrimental effect in MSI-H gastric cancer. In most previous studies related with adjuvant therapy in MSI-H gastric cancer, fluoropyrimidine and platinum combination was used. Fluoropyrimidine alone as an adjuvant chemotherapy in MIS-H gastric cancer was not evaluated. Therefore, adjuvant effect of fluoropyrimidine alone in MSI- 
Table 4. Multivariable analysis for disease-free survival and overall survival (cohort 2)

\begin{tabular}{|c|c|c|c|c|c|c|c|}
\hline \multirow[b]{2}{*}{ Characteristic } & \multirow[b]{2}{*}{ No. } & \multicolumn{3}{|c|}{ Disease-free survival } & \multicolumn{3}{|c|}{ Overall survival } \\
\hline & & $\begin{array}{c}\text { Hazard } \\
\text { ratio }\end{array}$ & $\begin{array}{c}95 \% \\
\text { Confidence } \\
\text { interval }\end{array}$ & p-value ${ }^{a)}$ & $\begin{array}{c}\text { Hazard } \\
\text { ratio }\end{array}$ & $\begin{array}{c}95 \% \\
\text { Confidence } \\
\text { interval }\end{array}$ & p-value ${ }^{a)}$ \\
\hline \multicolumn{8}{|l|}{ Sex } \\
\hline Male & 94 & 1 & & & 1 & & \\
\hline Female & 68 & 0.9 & $0.4-2.1$ & 0.939 & 0.9 & $0.4-1.8$ & 0.685 \\
\hline \multicolumn{8}{|l|}{ Age (yr) } \\
\hline$<70$ & 99 & 1 & & & 1 & & \\
\hline$\geq 70$ & 63 & 1.1 & $0.5-2.5$ & 0.771 & 2.4 & $1.1-5.3$ & 0.028 \\
\hline \multicolumn{8}{|l|}{ Lauren } \\
\hline Diffuse & 50 & 1 & & & 1 & & \\
\hline Intestinal & 85 & 0.7 & $0.3-1.5$ & 0.319 & 0.7 & $0.3-1.6$ & 0.443 \\
\hline Mixed & 27 & 0.4 & $0.1-1.5$ & 0.166 & 0.3 & $0.1-1.2$ & 0.076 \\
\hline \multicolumn{8}{|l|}{ Lymphatic invasion } \\
\hline Absent & 36 & 1 & & & 1 & & \\
\hline Present & 126 & 2.1 & $0.7-6.6$ & 0.184 & 0.9 & $0.4-2.3$ & 0.898 \\
\hline \multicolumn{8}{|l|}{ Venous invasion } \\
\hline Absent & 137 & 1 & & & 1 & & \\
\hline Present & 25 & 5.6 & $2.4-12.8$ & $<0.001$ & 2.0 & $0.8-4.9$ & 0.141 \\
\hline \multicolumn{8}{|l|}{ Perineural invasion } \\
\hline Absent & 101 & 1 & & & 1 & & \\
\hline Present & 61 & 1.0 & $0.5-2.1$ & 0.948 & 1.0 & $0.5-2.1$ & 0.960 \\
\hline \multicolumn{8}{|l|}{ Stage } \\
\hline II & 77 & 1 & & & 1 & & \\
\hline III & 85 & 2.1 & $0.9-4.9$ & 0.077 & 1.3 & $0.6-2.7$ & 0.553 \\
\hline \multicolumn{8}{|l|}{ Adjuvant chemotherapy } \\
\hline No adjuvant therapy & 75 & 1 & & & 1 & & \\
\hline Adjuvant chemotherapy & 82 & 0.4 & $0.2-1.0$ & 0.040 & 0.7 & $0.3-1.5$ & 0.327 \\
\hline
\end{tabular}

a)The Cox proportional hazards regression model was used.

$\mathrm{H}$ gastric cancer should be also evaluated in a further study.

In cases of MSI-H colorectal cancers, adjuvant chemotherapy with 5-fluorouracil alone may even have a detrimental effect on survival [8]. Therefore, recent guidelines do not recommend adjuvant chemotherapy with 5-fluorouracil alone in patients with MSI-H colorectal cancer $[10,11]$. However, it was reported that adding oxaliplatin could overcome this detrimental effect of 5-fluorouracil on patient survival in MSI-H colorectal cancers and that MSI-H alone did not affect survival in the case of adding oxaliplatin to treat stage III patients [21-24]. Inversely, in our study, adjuvant chemotherapy with fluoropyrimidine alone showed a benefit in terms of survival, which was different from the results obtained in colorectal cancer patients. It was reported that MSI status did not influence the survival of patients treated with 5-fluorouracil and the in vitro antitumor activity of 5 -fluorouracil in gastric cancer cells [25]. This difference between gastric cancer and colorectal cancer could be attributed to the biologic differences of MSI-H according to tumor type [26]. In our analysis for mutational profiles of MSI-H gastric and colorectal cancers from The Cancer Genome Atlas database, the mutational profile was different between gastric cancer and colon cancer (S5 Fig.). MSI-H colon cancer showed an increased rate of BRAF mutations compared with MSI-H gastric cancer (55\% vs. $22 \%$ ), but MSI-H gastric cancer exhibited more ARID1A, KMT2D, and RNF43 mutations than MSI-H colon cancer (S5 Fig.).

In conclusion, MSI-H tumor in patients with curatively resected gastric cancer had distinct characteristics with older age, intestinal type, other histology than poorly cohesive, signet ring cell type, lower third location, and absent perineural invasion. MSI-H could be a better prognostic marker in curatively resected gastric cancer. In MSI-H gastric cancer, adjuvant chemotherapy could show a survival benefit, which was in contrast to previous prospective studies and should be investigated in a further prospective trial.

\section{Electronic Supplementary Material}

Supplementary materials are available at Cancer Research and Treatment website (https://www.e-crt.org). 


\section{Conflicts of Interest}

Conflicts of interest relevant to this article was not reported.

\section{Acknowledgments}

This study was supported by grant no. 11-2012-010 from the SNUBH research fund.

\section{References}

1. Boland CR, Thibodeau SN, Hamilton SR, Sidransky D, Eshleman JR, Burt RW, et al. A National Cancer Institute Workshop on Microsatellite Instability for cancer detection and familial predisposition: development of international criteria for the determination of microsatellite instability in colorectal cancer. Cancer Res. 1998;58:5248-57.

2. Boland CR, Goel A. Microsatellite instability in colorectal cancer. Gastroenterology. 2010;138:2073-87.

3. Yuza K, Nagahashi M, Watanabe S, Takabe K, Wakai T. Hypermutation and microsatellite instability in gastrointestinal cancers. Oncotarget. 2017;8:112103-15.

4. Hause RJ, Pritchard CC, Shendure J, Salipante SJ. Classification and characterization of microsatellite instability across 18 cancer types. Nat Med. 2016;22:1342-50.

5. Buckowitz A, Knaebel HP, Benner A, Blaker H, Gebert J, Kienle $\mathrm{P}$, et al. Microsatellite instability in colorectal cancer is associated with local lymphocyte infiltration and low frequency of distant metastases. Br J Cancer. 2005;92:1746-53.

6. Marcus L, Lemery SJ, Keegan P, Pazdur R. FDA approval summary: pembrolizumab for the treatment of microsatellite instability-high solid tumors. Clin Cancer Res. 2019;25:3753-8.

7. Le DT, Uram JN, Wang H, Bartlett BR, Kemberling H, Eyring $\mathrm{AD}$, et al. PD-1 blockade in tumors with mismatch-repair deficiency. N Engl J Med. 2015;372:2509-20.

8. Sargent DJ, Marsoni S, Monges G, Thibodeau SN, Labianca R, Hamilton SR, et al. Defective mismatch repair as a predictive marker for lack of efficacy of fluorouracil-based adjuvant therapy in colon cancer. J Clin Oncol. 2010;28:3219-26.

9. Gryfe R, Kim H, Hsieh ET, Aronson MD, Holowaty EJ, Bull $\mathrm{SB}$, et al. Tumor microsatellite instability and clinical outcome in young patients with colorectal cancer. N Engl J Med. 2000;342:69-77.

10. Costas-Chavarri A, Nandakumar G, Temin S, Lopes G, Cervantes A, Cruz Correa M, et al. Treatment of patients with early-stage colorectal cancer: ASCO resource-stratified guideline. J Glob Oncol. 2019;5:1-19.

11. Labianca R, Nordlinger B, Beretta GD, Mosconi S, Mandala M, Cervantes A, et al. Early colon cancer: ESMO clinical practice guidelines for diagnosis, treatment and follow-up. Ann Oncol. 2013;24 Suppl 6:vi64-72.

12. Sasako M, Sakuramoto S, Katai H, Kinoshita T, Furukawa $\mathrm{H}$, Yamaguchi T, et al. Five-year outcomes of a randomized phase III trial comparing adjuvant chemotherapy with S-1 versus surgery alone in stage II or III gastric cancer. J Clin Oncol. 2011;29:4387-93.

13. Noh SH, Park SR, Yang HK, Chung HC, Chung IJ, Kim SW, et al. Adjuvant capecitabine plus oxaliplatin for gastric cancer after D2 gastrectomy (CLASSIC): 5-year follow-up of an openlabel, randomised phase 3 trial. Lancet Oncol. 2014;15:1389-96.
14. An JY, Kim H, Cheong JH, Hyung WJ, Kim H, Noh SH. Microsatellite instability in sporadic gastric cancer: its prognostic role and guidance for 5 -FU based chemotherapy after R0 resection. Int J Cancer. 2012;131:505-11.

15. Choi YY, Kim H, Shin SJ, Kim HY, Lee J, Yang HK, et al. Microsatellite instability and programmed cell death-ligand 1 expression in stage II/III gastric cancer: post hoc analysis of the CLASSIC randomized controlled study. Ann Surg. 2019; 270:309-16.

16. Pietrantonio F, Miceli R, Raimondi A, Kim YW, Kang WK, Langley RE, et al. Individual patient data meta-analysis of the value of microsatellite instability as a biomarker in gastric cancer. J Clin Oncol. 2019;37:3392-400.

17. Smyth EC, Wotherspoon A, Peckitt C, Gonzalez D, HulkkiWilson S, Eltahir Z, et al. Mismatch repair deficiency, microsatellite instability, and survival: an exploratory analysis of the Medical Research Council Adjuvant Gastric Infusional Chemotherapy (MAGIC) trial. JAMA Oncol. 2017;3:1197-203.

18. Cunningham D, Allum WH, Stenning SP, Thompson JN, Van de Velde CJ, Nicolson M, et al. Perioperative chemotherapy versus surgery alone for resectable gastroesophageal cancer. N Engl J Med. 2006;355:11-20.

19. Lee J, Lim DH, Kim S, Park SH, Park JO, Park YS, et al. Phase III trial comparing capecitabine plus cisplatin versus capecitabine plus cisplatin with concurrent capecitabine radiotherapy in completely resected gastric cancer with D2 lymph node dissection: the ARTIST trial. J Clin Oncol. 2012;30:268-73.

20. Bajetta E, Floriani I, Di Bartolomeo M, Labianca R, Falcone A, Di Costanzo F, et al. Randomized trial on adjuvant treatment with FOLFIRI followed by docetaxel and cisplatin versus 5-fluorouracil and folinic acid for radically resected gastric cancer. Ann Oncol. 2014;25:1373-8.

21. Gavin PG, Colangelo LH, Fumagalli D, Tanaka N, Remillard MY, Yothers G, et al. Mutation profiling and microsatellite instability in stage II and III colon cancer: an assessment of their prognostic and oxaliplatin predictive value. Clin Cancer Res. 2012;18:6531-41.

22. Kim ST, Lee J, Park SH, Park JO, Lim HY, Kang WK, et al. Clinical impact of microsatellite instability in colon cancer following adjuvant FOLFOX therapy. Cancer Chemother Pharmacol. 2010;66:659-67.

23. Oh SY, Kim DY, Kim YB, Suh KW. Oncologic outcomes after adjuvant chemotherapy using FOLFOX in MSI-H sporadic stage III colon cancer. World J Surg. 2013;37:2497-503.

24. Kim JE, Hong YS, Kim HJ, Kim KP, Kim SY, Lim SB, et al. Microsatellite instability was not associated with survival in stage III colon cancer treated with adjuvant chemotherapy of oxaliplatin and infusional 5-fluorouracil and leucovorin (FOLFOX). Ann Surg Oncol. 2017;24:1289-94. 
25. Oki E, Kakeji Y, Zhao Y, Yoshida R, Ando K, Masuda T, et al. Chemosensitivity and survival in gastric cancer patients with microsatellite instability. Ann Surg Oncol. 2009;16:2510-5.
26. Imai K, Yamamoto H. Carcinogenesis and microsatellite instability: the interrelationship between genetics and epigenetics. Carcinogenesis. 2008;29:673-80. 